\title{
Original Records: Tips on Their Handling
}

\author{
David J. Olson and William S. Price, Jr.
}

Many librarians find themselves in the sometimes uncomfortable position of having responsibility for a small collection of archival materials. Often this collection is in diverse formats-a scrapbook here, a shoe box of photographs there, a couple of diaries, some old letters, and perhaps a few original maps for good measure. For those trained in librarianship, such a shelf of curiosities may well be a nightmare. But the local historical society wants the library to keep them, the collection has been written up in the newspaper, and ther is just no easy way to dispose of it. So what to do with it?

Many librarians reserve an out-of-the-way shelf in some far place, maybe even put a neat label on it-"County Historical Society Collection"-and there the materials sit. Obviously, there must be a better way. However, it is in fact better to let the records sit idle than to damage them irreversibly through well-intentioned but misguided policy. What then is the "right way"? The answer is found partly in the history of archival practice, partly in procedures that manuscript collections have established, partly in common sense, and partly in a workable bibliographic knowledge of the field. This brief article will attempt to tie these aspects together to suggest a reasonable approach to handling original records.

One hallmark of a civilized society is that it attempts to preserve its identity for future generations in some kind of archival repository. Early cultures did this via clay tablets (which although fragile were relatively permanent), and more contemporary cultures have established programs based on preservation of their most important paper records for posterity. The United States waited until 1934 to establish a national archival facility in Washington, D.C. Before that, leadership in this area had come from state archival programs and the Library of Congress. All such

David J. Olson is Administrator of the Archives and Records Section, North Carolina Division of Archives and History, in Raleigh. William S. Price, Jr., is Director of the North Carolina Division of Archives and History. archival programs in the United States looked to European archival experience for leadership. Traditionally, American archival endeavors have been more pragmatic than their European counterparts in looking for workability before theoretical rectitude. As important archival institutions developed in the twentieth century, they turned to established manuscript institutions for their experience. In turn new repositories, often located on university campuses, developed and emphasized programs for private records. In the 1930 s a national Society of American Archivists was formed and a body of literature began growing to assist the developing archives/manuscripts profession. Certain basic principles were defined.

\section{Basic Principles}

Nineteenth-century European archival enterprises and their later American counterparts soon realized the futility of trying to impose on original paper materials any kind of subject classification scheme. It was apparent that the original source and order of the material had intrinsic meaning. Source of the records and the manner in which filing orders were devised and executed often said as much about a collection as the items themselves. Whether the scheme was chronological, alphabetical, subject file, or some number scheme, archivists soon realized that the original or intrinsic order should be preserved wherever possible and that the records created by one individual, family, or organization should not be intermingled with those created by other sources. The "horror" stories often told by archivists about collections where these concepts have been violated are legion. Suffice it to say that preservation of the original source and order is the most basic of archival principles.

What, then, do archivists or manuscript curators do when there is no order whatsoever in a collection? Then one does have to be arbitrary and impose the most plausible system-be it chronological, alphabetical, or a subject file. (Chronological order is the "safest bet.") But one must be sure there is no existing order before 
coming to this conclusion. Sometimes an order is not apparent at first because of numerous misfiles or dislocations caused by moving a collection. However, continual exposure to the material can reveal an order that was not seen at first. Caution is desirable because once a filing system has been destroyed, it can almost never be implemented again.

\section{Intellectual Controls}

A second basic principle is that the archivist/ manuscript curator should establish two kinds of control over the material: physical control and intellectual control. Physical controls will be discussed at some length in the next section of this article. Intellectual controls begin with accessioning. Often an accession numbering system is established through which temporary control is established over a collection until arrangement and description can be completed. This type of system should be simple-perhaps a ledger with an annual numbering scheme (i.e., 83-1 would mean the first collection accessioned in 1983) with a notation in the ledger by each number denoting what each collection is and its location. These numbers are placed on each separate filing container in the collection. After being accessioned, the material is stored until arrangement and description take place.

The arrangement of a collection involves its removal from the previous filing environment and placement in more stable archival containers. For papers this entails the use of acid-neutral folders as well as archival boxes also constructed of acidneutral materials. These supplies are available from archival suppliers such as Hollinger Corporation and Pohlig Brothers. ${ }^{1}$

Decisions need to be made at the time of arrangement as to what are the basic records ser$i e s$ in the material. A records series is defined as a group of records that has been brought together for a specific activity.

Once the material is arranged by series, it usually is apparent that several subseries exist as well. Often a fair amount of sorting by series and subseries is needed to deal with the misfiles and anomalies which result from transfer of the records. This is to be expected and should not be viewed as a violation of the original order. The arrangement procedure may be viewed as a kind of progressive "combing" of the collection, each time with a finer comb. At first, one simply inspects the material and arranges the existing boxes in some kind of plausible order. Then attempts are made to define the major series within the collection. Next the records are arranged by series. Then the subseries (if any) are found and arranged within the collection. As one proceeds, the records are moved from existing filing environments, placed into appropriate archival grade supplies, and temporarily labeled. The next step is the description of the collection so that the potential user may find what he or she is looking for. This can be an agonizing step for librarians, because archival description and library cataloging, while similar in purpose, are very different in practice. A collection of original documents is described in order to gain general access to a body of material. Archivists rarely attempt to guide the searcher to access at the individual item level. Rather, it is the purpose of an archival finding aid to direct the potential researcher to the box or two of materials that require study. The researcher must then do his or her own "finding." Two types of tools are usually prepared: one is an inventory listing of box and file folder headings, sometimes referred to as a preliminary inventory, and the other is a narrative description of content, usually referred to as the finding aid. It is useful to study published and unpublished funding aids and inventories from established institutions before selection of the appropriate format.

\section{Physical Controls}

The first step in establishing physical control over a collection is to make sure that unwanted "guests" are not a part of the collection. Such guests include silverfish, cockroaches, and other insects as well as mold and mildew, which can contaminate paper and photographic records. While most established archival institutions have some kind of fumigation chamber, one may not be available in many libraries. Insecticide sprays and anti-mold chemicals may be used in such instances. ${ }^{2}$

As George Cunha has pointed out, the major physical enemies of library/archival materials are:

People - However technical we become there is no avoiding the fact that the human error factor is the most common one in damage to unique materials. Such errors include - use of pressure sensitive tapes ("Scotch tapes");

-indiscriminate use of polyvinyl acetate and other synthetic materials;

-use of highly acidic paper for protective wrappers: 
- amateur laminations; and

-improper storage conditions.

The air we breathe - Environmental hazards, so acute for humans, also adversely affect paper. Sulfur dioxide pollution, particularly in urban environments, acutely affects archival/manuscript materials. Filtration systems in archival storage areas are needed in nearly any environment.

Light and Darkness - Prolonged exposure to ultraviolet rays may adversely affect materials, as does the daily light-dark cycle (if the materials are exposed). However, too much darkness may also adversely affect materials by encouraging the presence of pests such as fungi and vermin. Thus a low constant level of non-ultraviolet light is preferred.

Heat - Fluctuation of temperature, especially too much heat, is an environmental hazard. Mold is encouraged in too warm an environment. A temperature range of sixtyeight to seventy degrees is preferred for storage of paper records. ${ }^{3}$

Moisture - Humidity - too much of itencourages mold. A steady fifty percent humidity is preferred. In addition, leaky roofs and pipes pose obvious hazards. In cases of fire, excess water to extinguish the blaze causes as much or more damage than the fire.

Vermin - The need for fumigation has already been mentioned.

Acid - No library or archives is safe from acid. While other enemies listed above are easily identified, acid damage is frequently undetected. Acid usually becomes imbedded in paper at manufacture, although it can also migrate into paper from its surrounding storage media. It slowly destroys paper from within. Neutral pH is 7.0. A pH from 7 to 14 is increasingly alkaline and from 7 downward is on the acidic side of the scale. Some early papers were made from pure rag content and are remarkably free of acid, while other more recent paper may be very acidic. "Archivist's Pens" and other simple devices to measure acidity are available from the archival supply companies mentioned earlier. They will readily identify any acid problems in a collection.

The repair of damaged archival/manuscript materials is an arcane speciality often reserved for conservators and technicians. ${ }^{4}$ The North Carolina Division of Archives and History operates a laboratory in Raleigh where documentary lamination, encapsulation, and deacidification services are available on a cost basis to libraries and archival repositories throughout North Carolina. If simple repairs are to be attempted on site, the person making the repairs should carefully read the suggested literature and realize that reversibility is often impossible after repair. Thus the encapsulation of documents in acid-neutral plastic is often recommended since this process is readily reversible. Lamination using the Barrow process is recommended where document deterioration is advanced. This service, along with deacidification, is available in the Raleigh laboratory of the Division of Archives and History.

Space here does not permit adequate coverage of the physical care of non-textual records. The reader should consult Cunha's Conservation of Library Materials (page 35-36) for basic information on the care of photographs, motion picture films, and audio and video tapes.

\section{Reference Services}

Material is worth keeping only if it may be utilized by researchers. Any archival/manuscript endeavor should have well defined and regular hours during which material may be used by researchers. Since such material is original in nature, all archival repositories have "closed stack ${ }^{n}$ arrangements. Consequently, it is necessary to "pull" material for the researcher. Thus some kind of call slip system may well be needed. While all archivists uphold the widest possible use of their collections, it has become increasingly necessary to be aware of security techniques so that irreplaceable materials are not lost by theft. In the small repository, it is usually necessary for the reference staff to stay physically close to patrons using the materials. In larger repositories, television cameras and other such technological advances are often used to monitor patrons. To be effective, security measures must be applied equally to everyone, because archival thefts throughout the United States have shown that even the most "trusted researcher" has occasionally been involved in a theft.

\section{Collecting Strategies}

Once control has been established over the initial collection of materials, it is necessary to establish a cohesive strategy for collecting. Such a policy should be well defined, written, and exclusionary in nature. The small repository usually cannot collect widely on any subject. Perhaps the history of a county or municipality is the sum total of the collecting which is possible. There is a wealth of historical material in the field, and a 
responsible policy should be implemented in this area. Such a policy should not allow the splitting up of a collection already placed in part in another archival/manuscript repository. It should not allow for the collecting of public records which are provided for under law, and it should take into account the collecting done by other agencies in the area. Without a specific written policy, it is doubtful that an effective collecting effort can be carried out.

\section{Conclusion}

Ample guidance exists for the neophyte archivist. The selected bibliography following this article identifies helpful literature. Various national organizations, such as the Society of American Archivists and the American Association for State and Local History, offer publications and seminars directed towards the beginner. Universities throughout the country (and throughout North Carolina) offer courses in archival administration. Consultant services are available from a variety of sources. Therefore, the librarian who handles original sources should remember that he or she is not alone; help is available. Archivists at the North Carolina Division of Archives and History and at many other repositories throughout the state will make every reasonable effort to provide professional advice and assistance upon request.

\section{References}

1. Addresses: The Hollinger Corporation, Post Office Box 6185 , Arlington, Virginia 22206; Pohlig Bros., Inc., Post Office Box 8069 , Richmond, Virginia 23223.

2. George D. M. Cunha, Conservation of Library Materials (Metuchen, N.J.: Scarecrow Press, 1967), 333. This entire work provides a useful manual for the neophyte with lots of relevant "do's" and "don'ts." It has been used for this section of the article as a basic source.

3. Kenneth W. Duckett, Modern Manuscripts (Nashville: American Association for State and Local History, 1975), 90-92.

4. See Cunha, $350-355$, for a bibliography of sources on repair techniques.

\section{Selected Bibliography}

Bordin, Ruth B., and Robert M. Warner The Modern Manuscript Library. Scarecrow Press, 1966.

Cunha, George D. M. Conservation of Library Materials. Metuchen, N. J.: Scarecrow Press, 1967.

Duckett, Kenneth W. Modern Manuscripts: A Practical Manual for Their Management, Care and Use. Nashville; American Association for State and Local History, 1975.

Evans, Frank B. Modern Archives and Manuscripts: A Select Bibliography. Washington, D. C.: Society of American Archivists, 1975.

Hoy, Suellen M. Directory of North Carolina Historical Organizations. Raleigh: Federation of North Carolina Historical Societies, 1982.

Jones, H. G. Local Government Records: An Introduction to Their Management, Preservation, and Use. Nashville: American Association for State and Local History, 1980.

Schellenberg, Theodore R. Modern Archives: Principles and Techniques. Chicago: University of Chicago Press, 1956. 